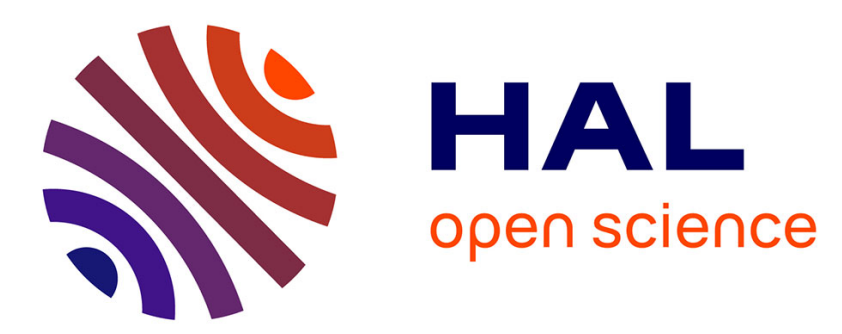

\title{
Modelling and design of all-organic electromechanic transducers
}

\author{
L. Fortuna, S. Graziani, M. La Rosa, D. Nicolosi, G. Sicurella, E. Umana
}

\section{To cite this version:}

L. Fortuna, S. Graziani, M. La Rosa, D. Nicolosi, G. Sicurella, et al.. Modelling and design of all-organic electromechanic transducers. European Physical Journal: Applied Physics, 2009, 46 (1), pp.1-4. 10.1051/epjap/2009019 . hal-00480149

\section{HAL Id: hal-00480149 \\ https://hal.science/hal-00480149}

Submitted on 3 May 2010

HAL is a multi-disciplinary open access archive for the deposit and dissemination of scientific research documents, whether they are published or not. The documents may come from teaching and research institutions in France or abroad, or from public or private research centers.
L'archive ouverte pluridisciplinaire HAL, est destinée au dépôt et à la diffusion de documents scientifiques de niveau recherche, publiés ou non, émanant des établissements d'enseignement et de recherche français ou étrangers, des laboratoires publics ou privés. 
EPJ manuscript No.

(will be inserted by the editor)

\title{
Modelling and Design of All-Organic Electromechanic Transducers
}

\author{
L. Fortuna ${ }^{1}$, S. Graziani ${ }^{1}$, M. La Rosa ${ }^{2}$, D. Nicolosi ${ }^{1,2}$, G. Sicurella ${ }^{1,2}$, and E. Umana ${ }^{1}$
}

1 Dipartimento di Ingegneria Elettrica Elettronica e dei Sistemi, Universitá degli Studi di Catania Viale A. Doria 6, 95125 Catania (CT), Italy. e-mail: : umana@diees.unict.it Phone: + 390956367455 Fax: +390956367569

2 Post Silicon Technologies Group, Technology R\&D, ST Microelectronics Stradale Primosole 50, 95121 Catania (CT), Italy

Received: date / Revised version: date

\begin{abstract}
The recent development of innovative organic materials with intriguing features such as their flexibility, lightness, low cost and easy manufacturability, has driven researchers to develop innovative smart applications based on such kind of materials. In this work, all - organic electromechanical transducers, with both sensing and acting capabilities are proposed. The actuator and sensor models have been identified by using a grey box approach, as a function of membrane geometric parameters. The obtained models have been validated through comparison among estimated and experimental data.
\end{abstract}

PACS. 07.05.Tp Computer modeling and simulation - 43.60.Qv Signal processing instrumentation, integrated systems, smart transducers, devices and architectures, displays and interfaces for acoustic systems - 73.61.Ph Polymers; organic compounds

\section{Introduction}

In recent years a wide interest has been devoted to the research of innovative materials for the development of flexible electromechanical transducers. In particular, ElectroActive Polymers (EAPs) have been extensively investigated because of their flexibility and lightness. Such kind of materials bends when solicited by an external electric field or an external voltage and act as motion sensor when an external deformation is applied. Among these materials Ionic Polymer Metal Composites (IPMCs) exhibit large bending when solicited with an external low voltage and produce an output current when an external deformation is applied. Such composites are constituted by an ion exchange perfluorinated membrane (usually Nafion ${ }^{\circledR} 115$ or Nafion ${ }^{\circledR} 117$ ), coated on both sides with a metallic electrode, generally a noble metal such as platinum is used [1]. In this work, all-organic electromechanical transducers are proposed. The device metallic electrodes are substituted with an organic conductor coating layer, such as PEDOT/PSS or Polyaniline (PANI). The obtained Ionic Polymer Polymer Composites ( $\mathrm{IP}^{2} \mathrm{Cs}$ ) have already demonstrated both sensing and acting features [2]. In order to fully exploit these all-organic electromechanic transducers features, their behaviour must be characterized thus enabling the development of novel smart applications. Is therefore fundamental the development of a model describing the $\mathrm{IP}^{2} \mathrm{C}$ behaviour considering the presence of nonlinearities. Starting from previous model developed for EAP actuators and sensors [3][6], considering a beam in cantilever configuration, the actuator and sensor model parameters have been identified using a grey box approach, as a function of membrane geometric parameters. The models have been validated trough comparison among estimated and experimental data. It is demonstrated how the design of flexible all-organic electromechanical transducers is enabled by adopting the identified models and suitable material technologies.

\section{Devices Manufacturing}

The Nafion ${ }^{\circledR}$ membrane, which is the core element of the $\mathrm{IP}^{2} \mathrm{C}$ devices, is first subjected to a sandblasting process in order to ensure the electrode mechanical adhesion and then cleaned by both ultrasonic and chemical bath (by boiling $\mathrm{HCl}(2.5 \mathrm{M})$ and by boiling water). Then the $\mathrm{IP}^{2} \mathrm{C}$ devices have been realized by covering Nafion ${ }^{\circledR} 117$ membranes with an organic conductor in order to realize the device electrodes. The conductor of choice has been, according to previous results[2], the PEDOT/PSS. In particular Orgacon ${ }^{T M} 3040$ conductor furnished by AGFA has been used. Among the possible manufacturing techniques the drop casting one gave the best results and has therefore been chosen. Nafion ${ }^{\circledR}$ strips of $3.0 \mathrm{~cm} \times 4.0 \mathrm{~cm}$ size fixed on a petri dish have been covered with the organic conductor solution and then left in ambient air for about three days until solvent evaporation from the substrate took place, then the procedure has been repeated over the other side. Strips of different size have been cut with length $\boldsymbol{L}_{t o t}$ ranging from 1 up to $3 \mathrm{~cm}$ and $\boldsymbol{w}=5 \mathrm{~mm}$. 
The membrane geometrical parameters are summarized in the following Fig. 1

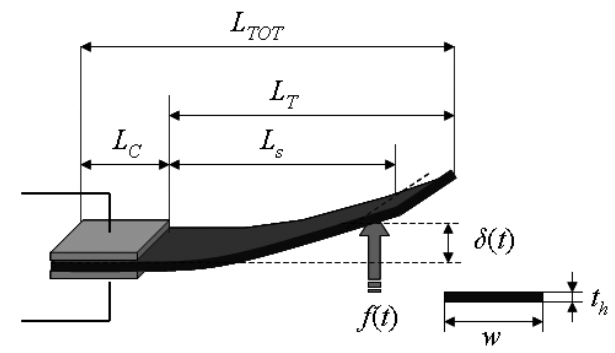

Fig. 1. Parameters characterizing the actuator and sensor devices

The value $\boldsymbol{t}_{h}$ takes into account the Nafion ${ }^{\circledR} 117$ thickness $(178 \mathrm{~m})$ plus the organic electrodes thickness; $\boldsymbol{w}$ is the membrane width, $\boldsymbol{L}_{T O T}$ is the membrane length, $\boldsymbol{L}_{t}$ is the length of the free membrane, $\boldsymbol{L}_{c}$ is the clamped part length. $\boldsymbol{L}_{S}$ is the point in which the force is applied, $\delta$ is the obtained displacement and $\boldsymbol{f}$ the blocking/applied force.

\section{IP ${ }^{2} \mathrm{C}$ actuator linear model}

In this chapter a linear model to describe the all-organic actuator electrical behavior is presented. The model is based on a grey box approach, in particular a lumped parameters equivalent circuit is presented to describe the electrical behavior of an $\mathrm{IP}^{2} \mathrm{C}$ actuator in cantilever configuration. The model is parameterized according the actuator geometrical dimensions shown in Fig. 1 The electric equivalent circuit model performs the conversion between applied voltage $\boldsymbol{V}_{I N}(t)$ and actuator absorbed current $\boldsymbol{I}_{\text {absorbed }}(t)$ as schematically shown in Fig. 2

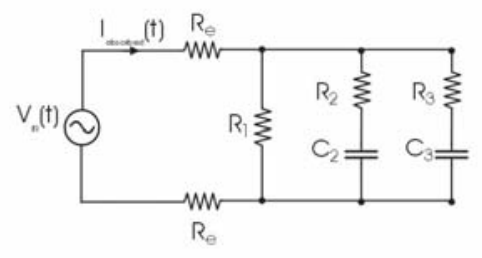

Fig. 2. $\mathrm{IP}^{2} \mathrm{C}$ actuator equivalent electric linear circuit

The circuit comprises two RC branches, introduced to model the capacitive nature intrinsic of the device structure, two resistances $\boldsymbol{R}_{e}$ modelling the organic conductors effect, and a resistance $\boldsymbol{R}_{1}$ which is the equivalent bulk resistance of Nafion ${ }^{\circledR}$ in DC conditions. In order to parameterize the model as a function of membrane dimensions the resistance $\boldsymbol{R}_{1}$ is expressed in terms of the Nafion ${ }^{\circledR}$ DC resistivity $\rho_{1}$ and actuator dimensions:

$$
R_{1}=\left(\rho_{1} \cdot t_{h}\right) /\left(L_{T O T} \cdot w\right)
$$

the value of $\rho_{1}$ according Dupont datasheets is $\rho_{1}=1205 \Omega \mathrm{m}$.

To the same purpose the resistances $\boldsymbol{R}_{2}$ and $\boldsymbol{R}_{3}$ and capacitors $\boldsymbol{C}_{2}$ and $\boldsymbol{C}_{3}$ have been expressed in terms of the resistivities $\left(\rho_{2}\right.$ and $\left.\rho_{3}\right)$ and permittivities ( $\epsilon_{2}$ and $\left.\epsilon_{3}\right)$ respectively and actuator geometric quantities according to the following relations:

$$
\begin{gathered}
R_{e}=R s \cdot L_{T} / w \\
R_{2}=\left(\rho_{2} \cdot t_{h}\right) /\left(L_{T O T} \cdot w\right) \\
R_{3}=\left(\rho_{3} \cdot t_{h}\right) /\left(L_{T O T} \cdot w\right) \\
C_{2}=\left(\epsilon_{2} \cdot L_{T O T} \cdot w\right) / t_{h} \\
C_{3}=\left(\epsilon_{3} \cdot L_{T O T} \cdot w\right) / t_{h}
\end{gathered}
$$

$\boldsymbol{R}_{e}$ is also expressed as a function of actuator dimensions and an opportune parameter $\boldsymbol{R}_{s}$ which must be identified. The system transfer function

$$
G(s)=\frac{I_{a b s}}{V_{i n}}
$$

is the system equivalent admittance that can be obtained by evaluating the inverse of equivalent impedance $Z_{e}$ :

$Z_{e}=\frac{V_{i n}}{I_{a b s}}=2 \cdot R_{e}+\left(R_{1} / /\left(R_{2}+\frac{1}{s C_{2}}\right) / /\left(R_{3}+\frac{1}{s C_{3}}\right)\right)$

\subsection{Parameters Identification}

Model identification has been performed on samples having the following dimension: $\boldsymbol{L}_{t}=15 \mathrm{~mm} ; \boldsymbol{L}_{c}=5 \mathrm{~mm} ; \boldsymbol{w}=$ $5 \mathrm{~mm} ; \boldsymbol{t}_{h}=200 \Omega \mathrm{m}$; The actuator model is characterized by five parameters $\boldsymbol{R}_{s}, \rho_{2} \rho_{3} \epsilon_{2}$ and $\epsilon_{3}$ which must be identified. Parameters identification has been performed in Matlab ${ }^{\circledR}$ by minimizing a cost function $\boldsymbol{J}_{i}$ which evaluates the error between measured and estimated absorbed current:

$$
J_{i}=\frac{\sqrt{\sum\left(I_{\text {absorbed }}-I_{\text {estimated }}\right)^{2}}}{\sqrt{\sum\left(I_{\text {absorbed }}\right)^{2}}}
$$

In order to identify the equivalent electric circuit parameters the membrane has been solicited with a frequency sweep voltage from $1 \mathrm{mHz}$ up to $200 \mathrm{~Hz}$ and $6 \mathrm{Vpp}$ amplitude. Data conditioning and acquisition has been performed through an ad hoc realized experimental setup shown in Fig. 3.

Both the input voltage and the absorbed current have been acquired by using the acquisition card DAQ 6052 by National Instruments ${ }^{T M}$. In the following figure an example of the acquired and estimated currents is plotted with different levels of detail. 


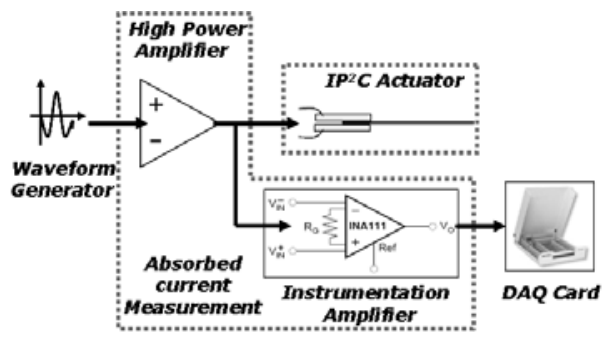

Fig. 3. Experimental setup used for the $\mathrm{IP}^{2} \mathrm{C}$ actuator electric model identification.

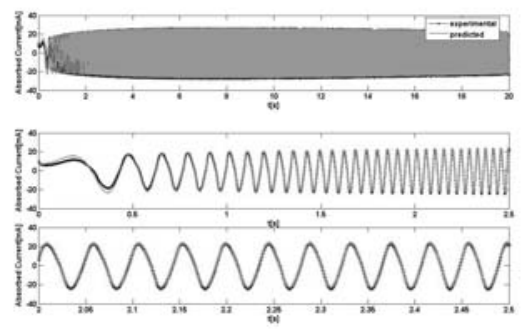

Fig. 4. Example of experimental and estimated absorbed current.

Table 1. $\mathrm{IP}^{2} \mathrm{C}$ Actuator Model Parameters

\begin{tabular}{ccccc}
\hline$R_{s}[\Omega m / m]$ & $\rho_{2}[\Omega m]$ & $\epsilon_{2}[F / m]$ & $\rho_{3}[\Omega m]$ & $\epsilon_{3}[F / m]$ \\
\hline 52.5806 & 25.6888 & 0.0059 & 0.0021 & 0.0003 \\
\hline
\end{tabular}

The obtained parameter values are reported in Table 1.

The identified electric model has been validated by using a white noise input signal with uniform distribution. Experimental and predicted currents are shown in Fig. 5.

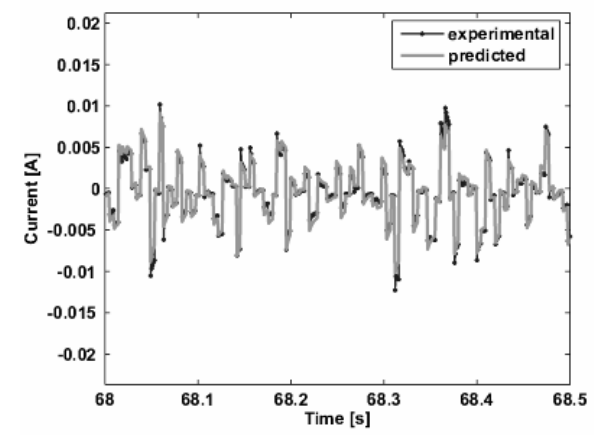

Fig. 5. Model validation.

\section{IP $^{2} \mathrm{C}$ sensor model}

The $\mathrm{IP}^{2} \mathrm{C}$ membranes demonstrated sensor capabilities to detect mechanical deformation. An $\mathrm{IP}^{2} \mathrm{C}$ sensor device structure is shown in Fig. 1, where $\boldsymbol{f}(\boldsymbol{t})$ is the applied force, $\delta(t)$ is the deflection of the beam and $\boldsymbol{I}_{S}(t)$ obtained in short-circuit condition.

Assuming the reciprocity of piezoelectric effect, the relation (10) between the input displacement $\delta(t)$ and the sensing current $\boldsymbol{i}_{s}(t)$ in the frequency domain can be found $[6]$.

$$
\frac{i_{S}(s)}{\delta(s)}=\frac{3 t_{h} w}{4 L_{S}} s Y(s) d(s)
$$

This relation models the electromechanical transduction properties of the polymeric membrane. The frequency dependent quantities $\boldsymbol{Y}(s)$ and $\boldsymbol{d}(s)$ represent respectively the Young's modulus and the piezoelectric coupling of the $\mathrm{IP}^{2} \mathrm{C}$ sensor. The hydration conditions of the $\mathrm{IP}^{2} \mathrm{C}$ membrane determine the value of the complex Young's modulus, mainly at very low frequencies. Moreover, when the membrane is wet in equilibrium with the environment in air, the Young's modulus becomes constant in the considered range of frequencies (less than $500 \mathrm{~Hz}$ ). The piezoelectric term $\boldsymbol{d}(s)$, which derives from the theory of piezoelectricity, has been introduced to model the electromechanical coupling of the $\mathrm{IP}^{2} \mathrm{C}$ sensor. Different structures have been considered for the relation that describe the complex function $\boldsymbol{d}(s)$. However, the experimental results show a single pole behavior in the considered frequency range (from $50 \mathrm{mHz}$ to $500 \mathrm{~Hz}$ ), thus (12) has been adopted to describe the piezoelectric coupling term.

$$
d(s)=\frac{k}{(s+\alpha)}
$$

The expressions of $\boldsymbol{d}(\boldsymbol{s})$ and $\boldsymbol{Y}$ can be obtained through experimental measurements by means of a minimization algorithm which uses both the electromechanical model expressed in ( 10) and the Euler-Bernoulli pinned beam theory (12).

$$
Y(s)=\frac{4 L_{S}^{3}}{w t_{h}^{3}} \cdot \frac{f(s)}{\delta(s)}
$$

In order to obtain the $\mathrm{IP}^{2} \mathrm{C}$ sensor model parameters, the experimental setup has been designed to measure at the same time both the imposed force, the displacement and the sensing current generated by the membrane. The forcing signal has been chosen to stimulate the transducer in the frequency range of interest. It is composed by a sequence of bipolar impulses, a bilateral chirp signal (from DC to $10 \mathrm{~Hz}$ ) and a random noise of increasing amplitude as shown in Fig. 6. Young's modulus has been identified through minimization of an index $\boldsymbol{J}_{Y}$ which is function of the time series of measured displacement $\delta^{r e a l}(t)$ and the predicted displacement $\delta^{\text {predicted }}(t)$ obtained from EulerBernoulli model.

The obtained value of Young's modulus $\boldsymbol{Y}$ has been substituted in (10) in order to identify the piezoelectric coupling parameters $\boldsymbol{k}$ and $\alpha$ whose values have been estimated through the minimizazion of a second index $\boldsymbol{J}_{d}$ which is function of the time series of both measured sense current $\boldsymbol{I}_{S}^{\text {real }}(t)$ and predicted sense current $\boldsymbol{I}_{S}^{\text {predicted }}(t)$ 

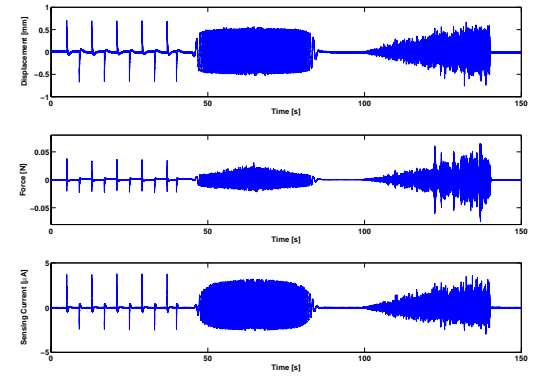

Fig. 6. Experimental data: displacement, force and sensing current.

Table 2. $I P^{2} C$ sensor model parameters.

\begin{tabular}{ccc}
\hline$Y[G P a]$ & $k\left[C s N^{-1}\right]$ & $\alpha[H z]$ \\
\hline 4.60 & $2.14 \cdot 10^{-8}$ & 13.08 \\
\hline
\end{tabular}

The values obtained by the minimization of index $\boldsymbol{J}_{d}$ are shown in table 2 .

The $\mathrm{IP}^{2} \mathrm{C}$ sensor model has been validated both in time and frequency domain by comparing measured and predicted values of sensing current time series and electromechanical transfer function bode diagrams. An electric equivalent circuit has been obtained starting from the electromechanical model of $\mathrm{IP}^{2} \mathrm{C}$ sensor, as shown in Fig. 7 .

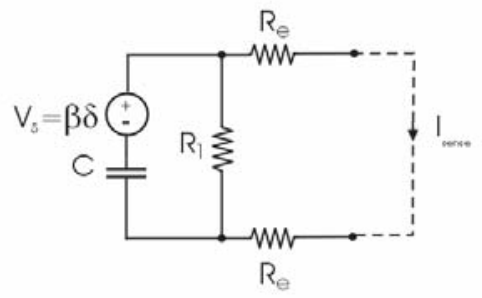

Fig. 7. Electric equivalent circuit of $I P^{2} C$ sensor model

As for the $\mathrm{IP}^{2} \mathrm{C}$ actuator model, the resistance $\boldsymbol{R}_{e}$ models the organic conductor resistance while $\boldsymbol{R}_{1}$ is the equivalent bulk resistance of Nafion ${ }^{\circledR}$ in DC conditions. The electromechanical transduction has been modeled by means of the voltage source generator $\boldsymbol{V}_{d}$ controlled by the displacement $\delta(t)$ and the capacitance $\boldsymbol{C}$, where

$$
C=\frac{\left(\epsilon \cdot L_{T O T} \cdot w\right)}{t_{h}}
$$

The term $\beta$ is a proportionality coefficient which realizes a coupling between displacement and voltage. The relations which associate the electric circuit parameters $\epsilon$ and $\beta$ to the electromechanical model parameters are expressed by (14) and (15) where $\boldsymbol{R}_{p}$ is the equivalent parallel resistance between $\boldsymbol{R}_{1}$ and $\left(2 \cdot R_{e}\right)$.

$$
\begin{gathered}
\epsilon=\frac{t_{h}}{L_{\text {TOT }} w \alpha R_{p}} \\
\beta=\frac{3}{2} t_{h} Y k R_{s}
\end{gathered}
$$

The obtained normalized circuit parameter values are reported in the following table:

Table 3. $I P^{2} C$ Sensor equivalent circuit parameters.

\begin{tabular}{ccc}
\hline$R_{s}[\Omega m / m]$ & $\beta[V / m]$ & $\epsilon[F / m]$ \\
\hline 52.5806 & 1.5514 & $6.226 \cdot 10^{-4}$ \\
\hline
\end{tabular}

\section{Conclusions}

All organic electromechanical transducers with acting and sensing features have been modelled by means of a grey box approach. In both cases a lumped parameters equivalent circuit has been adopted to model the devices dynamics. The proposed models have been validated through comparison among estimated and experimental data. It is demonstrated how the design of flexible all-organic electromechanical transducers is enabled by adopting the identified models and suitable material technologies.

\section{References}

1. M. Shahinpoor, K. J. Kim, Smart Materials and Structures, 10, (2001) 819-833

2. G. Di Pasquale, L. Fortuna, S. Graziani, M. La Rosa, D. Nicolosi, G. Sicurella, E. Umana, in the Proceedings of the IEEE I2MTC/08, Victoria, Vancouver Island, Canada, 2008.

3. K.M. Newbury, Ph.D.Thesis, Virginia Tech. University, 2002.

4. C. Bonomo, L. Fortuna, P. Giannone, S. Graziani, S. Strazzeri, in the Proceedings of the IEEE IMTC/05, Ottawa, Canada,2005.

5. C. Bonomo, L. Fortuna, P. Giannone, S. Graziani, S. Strazzeri, in the Proceedings EAPAD-SPIE , San Diego, California, 2006.

6. C. Bonomo, L. Fortuna, P. Giannone, S. Graziani, S. Strazzeri, Smart Materials and Structures, 15, (2006) 749758 . 